\title{
Psychological predictors of eco-driving: A longitudinal study
}

\author{
Elisabeth Lauper ${ }^{\mathrm{a}, \mathrm{b}, *}$, Stephanie Moser $^{\mathrm{b}}$, Maja Fischer ${ }^{\mathrm{b}, 1}$, Ellen Matthies ${ }^{\mathrm{c}}$, \\ Ruth Kaufmann-Hayoz ${ }^{\mathrm{d}}$ \\ ${ }^{a}$ Department of Psychology, University of Bern, Fabrikstrasse 8, 3012 Bern, Switzerland \\ ${ }^{\mathrm{b}}$ Centre for Development and Environment, University of Bern, Hallerstrasse 10, 3012 Bern, Switzerland \\ ${ }^{\mathrm{c}}$ Otto-von-Guericke University Magdeburg, Psychological Institute - Section for Environmental Psychology, Post Box 4120,39016 Magdeburg, Germany \\ ${ }^{\mathrm{d}}$ University of Bern, Hubelstrasse 17, 3052 Zollikofen, Switzerland
}

\section{A R T I C L E I N F O}

\section{Article history:}

Received 4 September 2014

Received in revised form 11 May 2015

Accepted 18 June 2015

Available online 6 July 2015

\section{Keywords:}

Eco-driving

Road-traffic noise

Theory of planned behavior

Health action process approach

\begin{abstract}
A B S T R A C T
Eco-driving has well-known positive effects on fuel economy and greenhouse-gas emissions. Moreover, eco-driving reduces road-traffic noise, which is a serious threat to the health and well-being of many people. We investigated the psychological predictors of the adoption of eco-driving from the perspective of road-traffic noise abatement. The data came from 890 car drivers who participated in a longitudinal survey over four months. Specifically, we tested the effects of the intention to prevent road-traffic noise, variables derived from the theory of planned behavior (social norm, perceived behavioral control, and attitude), and variables derived from the health action process approach (implementation intention, maintenance self-efficacy, and action control) on the intention to practice eco-driving and on eco-driving behavior. The intention to prevent road-traffic noise was not linked to the intention to practice eco-driving. The strongest predictors of the intention to practice eco-driving were attitude and perceived behavioral control. The strongest predictor of eco-driving behavior was action control. The link between behavioral intention and behavior was weak, indicating that drivers have difficulties putting their intention to practice eco-driving into action. Therefore, intervention efforts should directly address and support the transition from intention to behavior. This could be accomplished by providing reminders, which help to maintain behavioral intention, and by providing behavior feedback, which helps car drivers to monitor their behavior.
\end{abstract}

(c) 2015 Elsevier Ltd. All rights reserved.

\section{Introduction}

Individual mobility in western countries is accompanied by undesired side effects on humans and the environment, such as massive consumption of non-renewable energy coupled with the emission of greenhouse gases (in particular $\mathrm{CO}_{2}$ ), as well as emissions of harmful road-traffic noise. A neglected measure for reducing $\mathrm{CO}_{2}$ emissions by saving fuel is the adoption of eco-driving (Barkenbus, 2010). Eco-driving includes a driving style that is mainly characterized by anticipating traffic flow, maintaining a steady speed at low revolutions per minute, and shifting up early (Ecodrive.org., 2013b). Eco-driving has shown positive effects on fuel economy and greenhouse-gas emissions (e.g., Ericsson, 2001). Moreover, applying the

\footnotetext{
* Corresponding author at: Department of Psychology, University of Bern, Fabrikstrasse 8, 3012 Bern, Switzerland. Tel.: +4131631 3940.

E-mail addresses: elisabeth.lauper@psy.unibe.ch (E. Lauper), stephanie.moser@cde.unibe.ch (S. Moser), maja.fischer@cde.unibe.ch, maja.fischer@ppw. kuleuven.be (M. Fischer), ellen.matthies@ovgu.de (E. Matthies), ruth.kaufmann@emeriti.unibe.ch (R. Kaufmann-Hayoz).

${ }^{1}$ Current address: University of Leuven, Center for Social and Cultural Psychology/ Quantitative Psychology and Individual Differences, Tiensestraat 102, Box 3727, 3000 Leuven, Belgium.
} 
principles of eco-driving may significantly reduce road-traffic noise. One reason for this is that the noise produced by the engine is determined by the revolutions per minute (Eidgenoessische Materialpruefungs- und Forschungsanstalt, 1997). For example, the engine noise of one car running at $4000 \mathrm{rev} / \mathrm{min}$ is equal to the noise produced by 32 cars running at $2000 \mathrm{rev} / \mathrm{min}$ (Ecodrive.org., 2013a).

Road-traffic noise is a serious, but often neglected, environmental problem. The WHO recommends maximum noise levels of $55 \mathrm{~dB}(\mathrm{~A})$ during daytime (World Health Organization, 1999) and $40 \mathrm{~dB}(\mathrm{~A})$ during nighttime (World Health Organization, 2009). By these standards, 50\% of the Swiss population is exposed to harmful or annoying road-traffic noise during the day and 78\% at night (Swiss Federal Office for the Environment, 2014). Road-traffic noise is often combatted by means of technical and infrastructural changes (e.g., noise protection walls), but they are inapplicable in some places (e.g., due to lack of space or in town centers) and costly for municipalities. Consequently, road-traffic noise could be reduced more effectively by complementing measures that focus on technical and infrastructural changes with measures that focus on behavior change among car drivers (Vlek, 2005). Investigating factors that influence changes in motorists' noise-relevant behaviors (e.g., driving behavior) was the goal of a larger project on noise abatement (Schlachter et al., 2012), in which the present study is embedded. Accordingly, in this study we examine eco-driving from a noise-prevention perspective, because encouraging a shift in motorists' driving behavior to eco-driving may be a promising noise-abatement measure.

The adoption of eco-driving by individuals has so far been studied mainly from an energy-saving perspective. Several studies have documented the short-term and long-term impacts of eco-driving training (e.g., af Wåhlberg, 2007; Beusen et al., 2009) and have evaluated the influence of after-driving and real-time feedback concerning driving style on an individual's driving behavior (e.g., Barth \& Boriboonsomsin, 2009; Ericsson, Larsson, \& Brundell-Freij, 2006). In brief, intervention studies showed positive short- and long-term effects of eco-driving training, but these effects shrink over time; some drivers "forget" what they learned during the intervention (e.g., af Wåhlberg, 2007; Beusen et al., 2009).

There are no studies investigating the psychological aspects of eco-driving implementation, and only few studies have focused on motivation to practice eco-driving. Participants in a real-time intervention study showed a high motivation to adopt eco-driving after the intervention (Boriboonsomsin, Barth, \& Vu, 2011), and car drivers who participated in an online survey assessed the adoption of eco-driving as easy (Delhomme, Cristea, \& Paran, 2013). Another study showed, that the goal of increasing road safety and the goal of saving fuel were found to be more closely related to components of eco-driving (compliance with speed limits and time headways) than the goal of reducing air pollution (Cristea, Paran, \& Delhomme, 2012). In a recent study, Schießl, Fricke, and Staubach (2013) identified three motives of drivers concerning their driving style: a focus on time savings, a focus on the environment and on fuel consumption, and a focus on the possibility of changing one's own driving behavior.

A broader understanding of the psychological mechanisms underlying either the intention to practice eco-driving or putting this intention into practice might help to complement existing interventions with a view to overcoming the atrophy of intervention effects. Furthermore, no studies have investigated the adoption of eco-driving from the perspective of noise reduction. Therefore, the overall aim of this study was to gain insights into the process of eco-driving adoption in order to understand how this process can be enhanced and how eco-driving can serve to reduce road-traffic noise.

We have pursued this aim by testing a model to explain the adoption of eco-driving based on psychological theories, namely the theory of planned behavior (TPB; Ajzen, 1991; Fishbein \& Ajzen, 2010) and the health action process approach (HAPA; Schwarzer, 2008).

\subsection{Theory of planned behavior}

Driving behavior becomes automated through repetition, which means that the single actions of driving, such as changing gears or navigating, are frequently conducted with no conscious decisions being made. To change their driving behavior, car drivers have to change their automated behavior into deliberately controlled behavior - a process that requires considerable effort. First of all, therefore, car drivers need to be motivated to change their driving behavior (i.e., they need to form an intention to practice eco-driving), and second, they have to put this intention into practice. For the investigation of intention formation the TPB (Ajzen, 1991; Fishbein \& Ajzen, 2010), a theory that has frequently been used to investigate driving behavior, seems most suitable.

The TPB is based on the assumption that individuals make rational decisions. In the TPB, behavioral intention constitutes the motivational factor that influences behavior directly and that represents the effort individuals are willing to make in order to perform a behavior. Moreover, the TPB claims that behavioral intention mediates the relations between behavior and the three predictors attitude, perceived social norm, and perceived behavioral control.

Attitude represents the degree to which a person evaluates the behavior in question as favorable or unfavorable. Social norm captures the perceived social expectations of relevant others to perform or not to perform the behavior in question. Perceived behavioral control means the perceived ease or difficulty of performing the behavior in question. In addition to its effect via intention, perceived behavioral control may also predict behavior directly.

To our knowledge, the TPB has not previously been used to investigate eco-driving, but there are numerous TPB-based studies on other aspects of driving behavior. In particular, TPB is a suitable approach for predicting drivers' intention to comply with speed limits (Castanier, Deroche, \& Woodman, 2013; Cristea, Paran, \& Delhomme, 2013; Elliott, Armitage, \& Baughan, 2007; Parker, Manstead, Stradling, Reason, \& Baxter, 1992) and self-reported speeding behavior (Castanier et al., 2013; Cristea et al., 2013; Wallén Warner \& Åberg, 2006) or observed speeding behavior (Elliott et al., 2007; Wallén 
Warner \& Åberg, 2006). These studies found significant medium to large effects of behavioral intention on behavior, indicating that interventions fostering compliance with speed limits should focus on the predictors of behavioral intention. Attitude, perceived behavioral control, and perceived social norms are reported as significant predictors of behavioral intention, each with small to medium effect sizes.

However, most of the studies on driving behavior used cross-sectional data; therefore, interpretations about the causal directions of the effects from predictors on outcomes should be made with caution. Only a few studies used longitudinal data, measuring the predictors of driving behavior on one measurement occasion and the behavior at a later point in time, which allows for more reliable conclusions (Castanier et al., 2013; Elliott et al., 2007; Wallén Warner \& Åberg, 2006).

\subsection{Health action process approach}

A difficulty with using only the TPB for designing interventions is that even strong behavioral intentions do not automatically lead to the desired behavior (Webb \& Sheeran, 2006), especially in the case of automated practices such as driving style. Thus, enhancing only the intention to practice eco-driving might not have the desired behavior-change effect. Identifying predictors that complement behavioral intention might help to design more effective interventions to foster the regular practice of eco-driving. Unlike the TPB, which assumes that behavioral intentions lead directly to behavior, the HAPA proposes to distinguish two processes in behavior change: the motivational and the volitional process (Schwarzer, 2008). These two processes are influenced by different psychological predictors.

The motivational process consists in the formation of a behavioral intention. This intention to perform a certain behavior is considered a first step toward behavior change in both the HAPA and the TPB. Moreover, both theories propose some kind of evaluation of behavior as a predictor of behavioral intention. The HAPA proposes evaluation of the expected outcomes of the behavior in question, while the TPB views such outcome expectations, and the values individuals ascribe to them, as precursors of attitudes. Both theories propose the appraisal of one's own ability to perform the behavior in question as a second predictor of behavioral intention. In the TPB, this appraisal is called "perceived behavioral control", in the HAPA it is referred to as "task self-efficacy". Given that the HAPA has been developed for the investigation of health behavior, the perception of a threat to one's own health (risk perception) is conceived as a further factor influencing behavioral intention. The TPB provides no equivalent predictor. Conversely, in the TPB, social norm is a further predictor of intention, while the HAPA provides no comparable construct.

The volitional process consists in putting the behavioral intention into practice. In applications of the HAPA several predictors have been proposed that explain variance in behavior over and above behavioral intention. Among them are implementation intention, maintenance self-efficacy, and action control. Implementation intention captures the plans of when, where, and how to perform the behavior in question (e.g., Schwarzer et al., 2007; Sniehotta, Scholz, \& Schwarzer, 2005). Maintenance self-efficacy stands for optimistic beliefs about one's ability to deal with barriers on the way to establishing the behavior in question. Action control means active self-regulation, consisting of three dimensions: self-monitoring, awareness of own standards, and self-regulatory effort (e.g., Scholz, Nagy, Göhner, Luszczynska, \& Kliegel, 2009; Sniehotta et al., 2005). Awareness of own standards represents the constant individual awareness of intentions concerning a specific behavior. Self-monitoring is the constant observation of the behavioral intention put into practice. Self-regulatory effort describes one's own effort to reduce discrepancies between behavioral intentions and actual behavior.

The HAPA has frequently been used to explain behavior change in continuous and automated behaviors in health psychology, such as smoking, nutrition behavior, or seat belt use (e.g., Scholz, Keller, \& Perren, 2009; Scholz, Nagy, et al., 2009; Schwarzer, 2008; Schwarzer et al., 2007; Sniehotta et al., 2005). So far, no studies investigating driving behavior have used the HAPA. Moreover, only few studies have combined the TPB and the HAPA (e.g., Bamberg, 2013; Chow \& Mullan, 2010; Orbell et al., 2009).

\subsection{The present study}

In the present study, we used a combination of the TPB and the HAPA and longitudinal data to identify psychological factors that explain the adoption of eco-driving (see Fig. 1). More specifically, we adopted the HAPA's assumption that two processes can be distinguished in behavior change, namely the process of creating the intention to perform eco-driving and the process of putting this intention into practice. We used the predictors of the TPB to investigate behavioral intention and the predictors of the HAPA to investigate the process of putting the intention into practice.

In more detail, we first assumed attitude, social norm, and perceived behavioral control to be predictors of the intention to perform eco-driving. We made this assumption based on previous applications of the TPB to driving behavior (Elliott, Armitage, \& Baughan, 2003; Elliott et al., 2007; Forward, 2009; Parker et al., 1992; e.g., Wallén Warner \& Åberg, 2006). Because we were investigating eco-driving as a low-noise driving style, we also wanted to find out whether the intention to reduce road traffic noise is a further predictor of the intention to practice eco-driving.

In accordance with the HAPA, we further assumed implementation intention, maintenance self-efficacy, and action control to be predictors of behavior in addition to behavioral intention (e.g., Schwarzer, 2008; Schwarzer et al., 2007; Sniehotta et al., 2005). Maintenance self-efficacy and action control seemed to be especially important for a continuous behavior such as practicing eco-driving, because the goal is to automatize this driving style, i.e., it should be practiced again and again. 


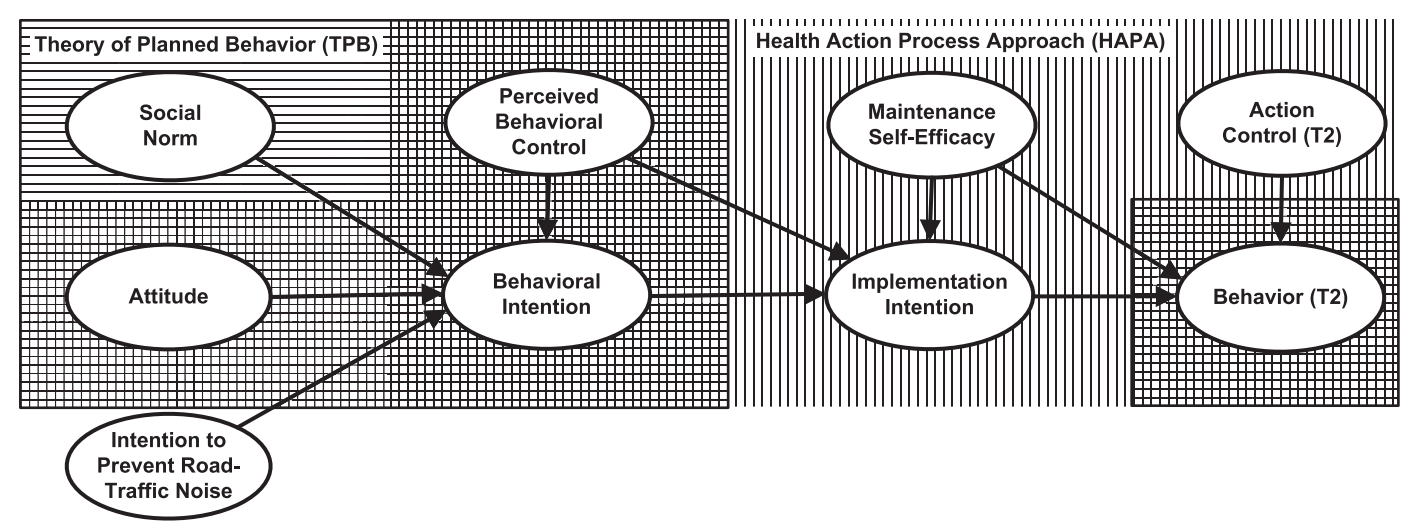

Fig. 1. Theoretical model, combination of the theory of planned behavior and the health action process approach. Horizontal stripes: constructs derived from TPB; vertical stripes: constructs derived from HAPA; checkered: constructs included in the TPB and in the HAPA. Behavioral intention = intention to practice eco-driving; behavior = repeated performance of eco-driving; T2 = Time 2 (i.e., follow-up assessment).

Using the model described above, we addressed the following two research questions: First, which predictors adopted from the TPB and the HAPA are predictors of a car driver's intention to practice eco-driving and of the transformation of this intention into action? Second, what are starting points for interventions that aim to foster eco-driving as a means of reducing road-traffic noise?

\section{Method}

We collected the data using a web-based longitudinal survey in Switzerland, consisting of a baseline survey (Time 1 in autumn 2011) and a follow-up assessment four months later (Time 2 in spring 2012). The study participants were required to be car drivers and therefore needed a driver's license (in Switzerland, the driver's license cannot be obtained before the age of 18). The participants were recruited using a database of individuals with a general interest in participating in psychological surveys, maintained at the University of Basel, and the database of Bachelor's, Master's, and PhD students enrolled at the University of Bern. Furthermore, the study was advertised on the Internet and by flyers available from firms (e.g., tire retailers, car and motorcycle retailers, and garages). The project website provided preliminary information about the purpose and procedure of the study. Visitors to the website were informed that all participants could take part in a lottery to win one of ten vouchers for online stores (with a value of 100 Swiss Francs, equivalent to US\$ 110). Upon providing a valid e-mail address, participants received their personal link to access the survey. They were informed that their responses would be treated as strictly confidential. Participants who registered their e-mail address but did not complete the survey were sent one e-mail reminder after one week. Four months after registering on the study website, participants received an invitation for the follow-up assessment. Participants who did not complete the follow-up were sent one e-mail reminder after one week. In the survey, eco-driving was introduced as a driving style that experts rated as safe, energy-efficient, and low-noise. Moreover, four important eco-driving rules for cars with manual and automatic transmission were presented.

\subsection{Participants}

In the baseline assessment, 890 individuals (53\% female) provided data on their car-driving behavior. The mean age of participants in the baseline assessment was 31.0 years $(S D=12.3$, range $=19-80)$. One percent had completed the obligatory 9 school years or less, 53\% had completed secondary education (approximately 12 years), 42\% had a Master's degree, and 4\% had a doctoral degree. The follow-up assessment was completed by 706 individuals (79\% response rate). To investigate the potential impact of dropouts, we examined differences in demographic variables between participants who completed both assessments and participants who did not complete the follow-up assessment. We found no significant differences in age, sex, or education.

\subsection{Measures}

Because no measures were available for the specific focus of this study (i.e., eco-driving), measures were adapted from the underlying theories. All responses were measured on a 6-point scale ranging from 1 (strongly disagree) to 6 (strongly agree). Variables were measured using three or more items. All measures were assessed in the baseline and the follow-up assessment. For theoretical reasons, the present research uses measures of action control and behavior from the follow-up assessment, and measures of all other variables from the baseline assessment. Thus, there is a clear temporal ordering of predictors (which are assessed at Time 1) and outcome (which is assessed at Time 2). The only exception is 
the action control variable (a predictor assessed at Time 2 ), because action control is measured retrospectively with regard to the past four months (see below); therefore, the Time 2 measure, not the Time 1 measure, of action control is the theoretically relevant predictor.

\subsubsection{Intention to prevent road-traffic noise}

Items were constructed with close reference to intention as proposed by Gärling, Fujii, Gärling, and Jakobsson (2003). The scale included three items (Cronbach's alpha $=.93$ ). An item example is: "I intend to keep the road-traffic noise I produce low."

\subsubsection{Attitude}

Items were constructed according to the TPB (Fishbein \& Ajzen, 2010). The scale included three items (Cronbach's alpha $=.88$ ). An item example is: "I think it is good to practice eco-driving."

\subsubsection{Social norm}

Items were constructed according to the TPB (Fishbein \& Ajzen, 2010). The scale included three items (Cronbach's alpha $=.92$ ). An item example is: "Most people who are important to me think I should practice eco-driving."

\subsubsection{Perceived behavioral control}

Items were constructed according to the TPB (Fishbein \& Ajzen, 2010). The scale included three items (Cronbach's alpha $=.79$ ). An item example is: "In principle, it is possible for me to practice eco-driving."

\subsubsection{Behavioral intention}

Items were constructed according to the TPB (Fishbein \& Ajzen, 2010). The scale included three items (Cronbach's alpha = .94). An item example is: "I intend to practice eco-driving in the next four months."

\subsubsection{Maintenance self-efficacy}

Items were constructed according to the HAPA and were adapted from the items used by Scholz, Sniehotta, and Schwarzer (2005). The scale included four items (Cronbach's alpha $=.80$ ). An item example is: "I am convinced that I will practice eco-driving even when I am not in the mood to do so."

\subsubsection{Implementation intention}

Items were constructed according to Dholakia and Bagozzi (2002). The scale included three items (Cronbach's alpha $=.96)$. An item example is: "I already know when I will practice eco-driving."

\subsubsection{Action control}

Items were constructed according to the HAPA and were adapted from the items used by Scholz, Keller, et al. (2009). The scale included three subscales (Cronbach's alpha $=.91$ ), namely, awareness of standards, self-monitoring, and self-regulatory efforts. Each subscale included three items. An item example for awareness of standards is: "In the last four months I have regularly thought about my resolution related to eco-driving." An item example for self-monitoring is: "In the last four months I have observed myself with regard to the principles of eco-driving". An item example of self-regulatory efforts is: "In the last four months I have done everything to practice eco-driving."

\subsubsection{Behavior}

Items were constructed according to the TPB (Fishbein \& Ajzen, 2010). The scale included three items (Cronbach's alpha $=.95)$. An item example is: "In the last four months I have always practiced eco-driving when driving."

\subsection{Statistical analyses}

The analyses were conducted by means of structural equation modeling (Kline, 2011) using the Amos 22 structural equation modeling program (Arbuckle, 2006). Missing values were replaced following the full information maximum likelihood procedure according to suggestions by Schafer and Graham (2002). To evaluate the model fit we used the Tucker-Lewis index (TLI), the comparative fit index (CFI), and the root-mean-square error of approximation (RMSEA). We applied cut-off values as proposed by Hu and Bentler $(1998,1999)$, saying that values of at least .95 for TLI and CFI and less than or equal to .06 for RMSEA indicate a good fit between the hypothesized model and the observed data.

\section{Results}

Table 1 shows means and standard deviations of the study variables. On average, the participants rated all constructs positively. The participants had a strong intention to practice eco-driving and perceived themselves as having considerable control over practicing eco-driving. Moreover, the attitude toward eco-driving and the implementation intention were on average rated as distinctly positive. The intention to prevent road traffic noise, social norms, and maintenance 
Table 1

Means and standard deviations of study variables.

\begin{tabular}{lll}
\hline Variable & $M$ & SD \\
\hline Intention to prevent road-traffic noise & 4.24 & 1.33 \\
Attitude & 4.87 & 1.08 \\
Social norm & 4.16 & 1.36 \\
Perceived behavioral control & 5.27 & 0.81 \\
Behavioral intention & 5.14 & 1.24 \\
Maintenance self-efficacy & 4.43 & 1.11 \\
Implementation intention & 4.77 & 1.47 \\
Action control & 3.66 & 1.46 \\
Behavior & 3.91 & 1.65 \\
\hline
\end{tabular}

Note: All responses were measured on a 6-point scale ranging from 1 (strongly disagree) to 6 (strongly agree).

self-efficacy were on average slightly less positive. The lowest ratings were accorded to action control and behavior, i.e. the regular practice of eco-driving.

We first tested the measurement model by conducting a confirmatory factor analysis. In contrast to structural models, measurement models do not include any direct paths between the latent constructs but exclusively correlational paths. Systematically relating all constructs included in the model makes it possible to test how well the model measures the latent constructs. The measurement model fits the data well, with $\chi^{2}(314)=1042.582, p<.05, \mathrm{TLI}=.95, \mathrm{CFI}=.96$, and RMSEA $=.051$ $(90 \%$ confidence interval of RMSEA $=.048-.055)$. The intercorrelations of the latent variables are shown in Table 2 . All correlations are significant and in the expected direction.

Second, we tested the structural model as shown in Fig. 2. Preliminary analyses showed that implementation intention is not a full mediator of the effect of behavioral intention on behavior. Therefore, we included a direct path from behavioral intention to behavior in the model. The structural model showed a satisfactory fit, with $\chi^{2}(324)=1106.274, p<.05$, $\mathrm{TLI}=.95, \mathrm{CFI}=.96$, and RMSEA $=.052(90 \%$ confidence interval of RMSEA $=.049-.055)$.

A considerable amount of variance in behavior (50\%) is explained by action control, maintenance self-efficacy, implementation intention, and behavioral intention, which all attained significant regression weights $(p<.05)$. With a beta of .47 , action control is the strongest predictor of behavior, while the direct and indirect effects of behavioral intention, implementation intention, perceived behavioral control, and maintenance self-efficacy are rather small. In other words, the intention to practice eco-driving does not automatically lead to the regular practice of eco-driving. The time, attention, and effort that are devoted to the regular practice of eco-driving are therefore more important than planning (implementation intention) or the beliefs in one's own ability (maintenance self-efficacy and perceived behavioral control).

Almost $40 \%$ of variance in implementation intention is explained by perceived behavioral control, behavioral intention, and maintenance self-efficacy. Importantly, the effect of perceived behavioral control $(\beta=.36, p<.05)$ had almost twice the size of the two other effects.

Variance in behavioral intention could be explained up to almost $60 \%$ by attitude and perceived behavioral control, while social norm had only a small effect on behavioral intention. Importantly, there was a weak connection between the intention to reduce road-traffic noise and behavioral intention, given that the TPB variables were controlled for. Moreover, the effect was in the unexpected direction.

Following the suggestion of an anonymous reviewer, we tested an additional model with a direct path from attitude to behavior. This structural model showed a satisfactory fit with $\chi^{2}(323)=1085.531, p<.05, \mathrm{TLI}=.95, \mathrm{CFI}=.96$, and RMSEA $=.052(90 \%$ confidence interval of RMSEA $=.048-.055)$. The standardized coefficient of the new path from attitude on behavior was .30. The direct effect from behavioral intention on behavior was no longer significant, but the indirect effect mediated by implementation intention was virtually unaltered and significant. Similarly, the direct effect of maintenance self-efficacy on behavior was no longer significant, but the indirect effect mediated by implementation intention was virtually unaltered and significant. The amount of explained variance in behavior was slightly larger (2\%). Thus, the overall conclusions from the model were similar, regardless of whether the direct path from attitude to behavior was included or not.

\section{Discussion}

The goal of the present study was to identify social psychological factors that explain the adoption of eco-driving from the perspective of noise abatement. We examined data from 890 Swiss car drivers who participated in a two-wave longitudinal online survey over four months. In the analyses, we examined a model that combines the TPB and the HAPA.

\subsection{Predicting eco-driving}

In the present study, the relation between the intention to practice eco-driving and the regular practice of eco-driving measured by means of self-reports is rather weak. The most important predictor of the regular practice of eco-driving is car drivers' perceived ability to actively self-regulate, i.e. action control. Action control was derived from the HAPA and is 
Table 2

Intercorrelations among latent variables from the model.

\begin{tabular}{|c|c|c|c|c|c|c|c|c|}
\hline Latent variables & 1 & 2 & 3 & 4 & 5 & 6 & 7 & 8 \\
\hline 1. Intention to prevent road-traffic noise & - & & & & & & & \\
\hline 2. Attitude & $.34^{*}$ & - & & & & & & \\
\hline 3. Social norm & $.23^{*}$ & $.54^{*}$ & - & & & & & \\
\hline 4. Perceived behavioral control & $.23^{*}$ & $.72^{*}$ & $.37^{*}$ & - & & & & \\
\hline 5. Behavioral intention & $.20^{*}$ & $.73^{*}$ & $.44^{*}$ & $.64^{*}$ & - & & & \\
\hline 6. Maintenance self-efficacy & $.31^{*}$ & $.64^{*}$ & $.35^{*}$ & $.57^{*}$ & $.56^{*}$ & - & & \\
\hline 7. Implementation intention & $.25^{*}$ & $.52^{*}$ & $.31^{*}$ & $.58^{*}$ & $.51^{*}$ & $.48^{*}$ & - & \\
\hline 8. Action control & $.26^{*}$ & $.53^{*}$ & $.32^{*}$ & $.37^{*}$ & $.43^{*}$ & $.47^{*}$ & .37 & - \\
\hline 9. Behavior & $.29^{*}$ & $.60^{*}$ & $.29^{*}$ & $.55^{*}$ & $.47^{*}$ & $.50^{*}$ & $.44^{*}$ & .64 \\
\hline
\end{tabular}

$p<.05$.

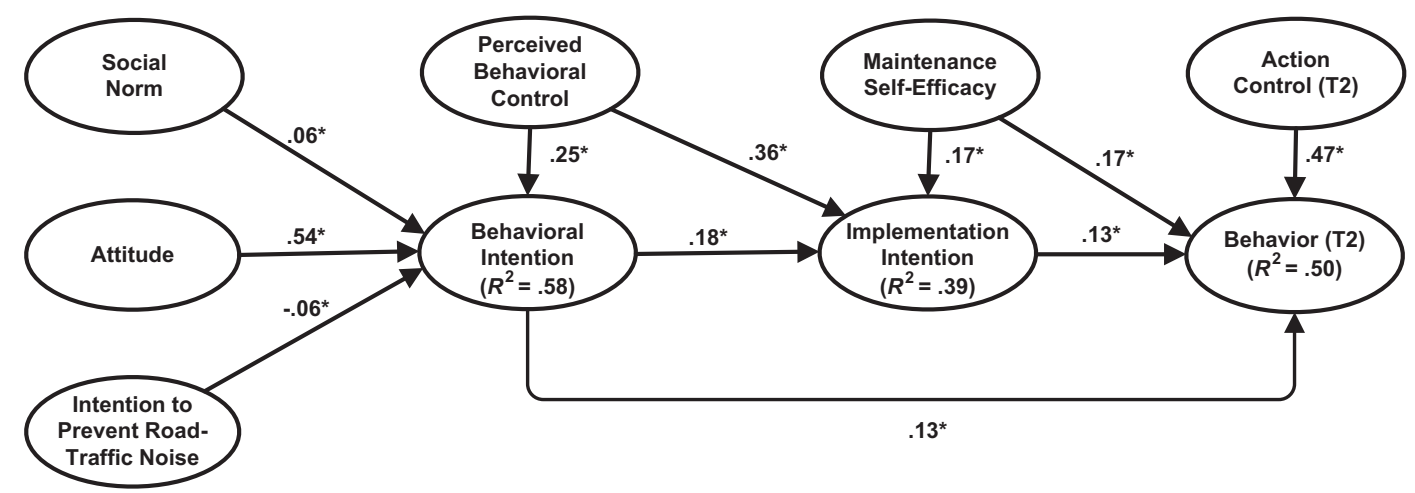

Fig. 2. Adoption of eco-driving, combination of the theory of planned behavior and the health action process approach. The figure shows standardized regression coefficients and explained variances $\left(R^{2}\right)$ of endogenous variables. To keep the figure simple, only latent variables are shown, whereas indicators, residual variances, and correlations between exogenous variables are omitted. Behavioral intention = intention to practice eco-driving; behavior = repeated performance of eco-driving; T2 = Time 2 (i.e., follow-up assessment). ${ }^{*} p<.05$.

comprised of three aspects: car drivers' constant awareness of their eco-driving intention, their constant observation of putting this intention into practice, and the effort they make to reduce discrepancies between eco-driving intention and the actual practice. The effect of action control on behavior was distinctly higher than the effects of its other three direct predictors: the intention to practice eco-driving, planning to put this intention into practice (implementation intention), and optimistic beliefs about one's ability to deal with barriers on the way to establishing the behavior in question (maintenance self-efficacy). Therefore, interventions that aim at fostering eco-driving among car drivers might be most successful if they address action control. The importance of action control as a predictor of regular behaviors has also been shown in recent applications of the HAPA to health behaviors such as dental flossing, physical exercise, nutrition behavior, and stopping smoking (Scholz, Nagy, et al., 2009; Schüz, Sniehotta, \& Schwarzer, 2007; Sniehotta, Nagy, Scholz, \& Schwarzer, 2006).

Although action control was the most important predictor of self-reported practice of eco-driving, including the whole set of proposed predictors might help get closer to bridging the so-called "intention-behavior gap" that is frequently pointed out in discussions of the TPB (Armitage \& Conner, 2001; Bamberg, 2013). Concretely, implementation intention, maintenance self-efficacy, and action control can all be starting points for interventions, especially when the behavioral intention is already very positive.

Even though behavioral intention was not a strong predictor of the regular practice of eco-driving, it constitutes the motivational basis for behavior change. Enhancing behavioral intention might be reasonable in populations with weak motivation to practice eco-driving. The most important predictors of the intention to practice eco-driving are attitude toward eco-driving and perceived behavioral control, while social norm only had a small effect on behavioral intention. Therefore, in a population with low motivation to practice eco-driving, interventions should address car drivers' attitude toward the behavior and enhance their perceived behavioral control.

Some minor importance of social norm on behavioral intention when perceived behavioral control and attitude were controlled for was also found in previous studies (Armitage \& Conner, 2001; Harland, Staats, \& Wilke, 1999). Our study supports this finding, as social norms had only a minor effect on behavioral intention if the other TPB variables were controlled for. But other studies have reported that social norms have a substantial direct or indirect effect on behavioral intention (Bamberg, Hunecke, \& Blöbaum, 2007; Bamberg \& Möser, 2007; Bamberg \& Schmidt, 2003; Heath \& Gifford, 2002; Klöckner \& Blöbaum, 2010; Wall, Devine-Wright, \& Mill, 2007). Studies investigating driving behavior generally found a significant effect of social norm on the intention to speed or on speeding behavior (Castanier et al., 2013; Cristea et al., 2013; Elliott et al., 2003, 2007; 
Parker et al., 1992; Wallén Warner \& Åberg, 2006). Therefore, we suggest that social norms should not be neglected in future studies on driving behavior. In the case of eco-driving, however, they seem to play a minor role.

A theoretically and practically important finding of our study is that the intention to prevent road-traffic noise is not linked to the intention to practice eco-driving. Other studies report a stronger link between general intentions (or goals) and behavioral intention when the content of the general intention is obviously connected to the target behavior (e.g., Bamberg, 2007). Since eco-driving is usually promoted by highlighting savings of fuel, money, and $\mathrm{CO}_{2}$ emissions, these reasons for practicing eco-driving might be well-known. As shown by Cristea et al. (2012), the motivations to save fuel and to enhance safety are more strongly related to eco-driving than the motivation to prevent air pollution. We therefore hypothesize that a connection between such goals (e.g., saving fuel, saving money, enhancing safety) and the intention to practice eco-driving may be found in future studies. Consequently, in fostering eco-driving it does not seem reasonable to focus only on road-traffic noise.

A last, theoretically meaningful, finding is that implementation intention is a partial mediator of the effect of behavioral intention on behavior. This finding suggests that implementation intention (i.e., a plan when, where, and how to practice eco-driving) is not a condition for moving from behavioral intention to behavior, but might be a supporting factor. Nevertheless, accounting simultaneously for both planning and implementation of an intended behavior seems to be promising and should be considered in future research.

\subsection{Implications for eco-driving interventions as means of noise abatement}

The missing link between the intention to prevent road-traffic noise and the intention to practice eco-driving in the present study has two implications for enhancing the intention to practice eco-driving. On the one hand, it might be more fruitful to promote eco-driving using other arguments than noise prevention. These arguments could include financial gains (fuel saving), safety aspects, and moral appeals $\left(\mathrm{CO}_{2}\right.$ reduction). On the other hand, given that the participants had, on average, a strong intention to avoid road-traffic noise, but that this intention did not seem to be linked to the intention to practice eco-driving, establishing this link could lead to a stronger intention to practice eco-driving.

However, in light of the fact that the intention to practice eco-driving had high mean scores in our sample, but that the direct and indirect effects of this intention on behavior were rather small, we conclude that interventions should not merely focus on enhancing behavioral intention but should directly address the transition to behavior realization, i.e., regular practice of eco-driving. In particular, this goal could be achieved by enhancing motorists' action control by addressing their awareness of their own standards, their self-monitoring, and their self-regulatory efforts (Sniehotta et al., 2005). In their classification of behavioral interventions, Mosler and Tobias (2007) distinguish between techniques that aim at changing individuals' preference for behavior (i.e., motivation) and techniques that encourage behavior change. Addressing action control falls into the second category. The sub-category of situation-focused techniques and, within that, the group of passive individual-focused techniques (e.g., reminders and cues) and the group of active individual-focused techniques (e.g., self-feedback and private commitment) seem suitable for enhancing action control.

Reminders could activate the recall of car drivers' intentions regarding eco-driving (i.e., their awareness of their own standards). Reminders could take the form, for example, of prompts printed on stickers. Prompts are short written messages or signs that indicate a specific behavior in a given situation (Steg, van den Berg, \& De Groot, 2012). They are more powerful when they make a specific request and when they are placed spatially and temporally close to the situation where the behavior in question occurs (Lehman \& Geller, 2004). Consequently, stickers should help car drivers to recall concrete behavioral aspects such as keeping engine revolutions below a critical value and should therefore be placed somewhere in the car or designed as a kind of car key fob. Moreover, prompts seem to be more effective when the attitude toward the target behavior is high (Schultz, Oskamp, \& Mainieri, 1995) - which is true in the case of eco-driving.

Self-monitoring can be fostered by motivating people to journalize their practice (Sniehotta et al., 2006). Journalizing can be done, for example, by using a logbook on a website or a smartphone app (Barth \& Boriboonsomsin, 2009; Ericsson et al., 2006). Computerized and interactive tools should be favored, because they allow tailored behavioral feedback, which has been found to be successful in the case of energy consumption (Fischer, 2008). Ideally, the feedback is combined with assigned or self-generated rather ambitious goals (Abrahamse, Steg, Vlek, \& Rothengatter, 2005). This might not only foster self-monitoring, but also enhance car drivers' self-regulatory effort by visualizing the discrepancy between intention and actual behavior. Moreover, such a feedback can show the positive consequences of the new behavior, such as fuel saving, road-traffic noise prevention, or $\mathrm{CO}_{2}$ emissions reduction and no time loss. Thus, feedback can help prevent relapses, by stabilizing attitude and perceived behavioral control, thereby keeping behavioral intention high. Importantly, feedback should focus on the environmental benefits of eco-driving more than on financial gains, because in the case of eco-driving, financial gains are rather small and therefore do not enhance behavioral intention, as was reported in a recent experimental study by Dogan, Bolderdijk, and Steg (2014).

Another means for providing reminders and feedback are advanced driver assistance systems. Such systems can deliver real-time or after-driving feedback, for example on fuel economy (e.g., Jenness, Singer, Walrath, \& Lubar, 2009) and optimal gear shifting and acceleration (van der Voort, Dougherty, \& van Maarseveen, 2001; Wu, Zhao, \& Ou, 2011). Research suggests that drivers prefer systems that only give feedback but do not intervene directly (e.g., Fricke \& Schießl, 2011). However, the development of advanced driver assistance systems takes a long time, whereas smartphone apps and websites can be developed and implemented fairly rapidly. 


\subsection{Limitations and future research}

The present results have theoretical implications for the investigation of driving behavior, especially eco-driving. Our combined model provides a meaningful description of the adoption of eco-driving. The social psychological factors explained a large proportion of variance of the intention to practice eco-driving and of putting this intention into practice (i.e., regular practice of eco-driving).

Nevertheless, several limitations of our study should be noted. First, given that the present research investigated self-reported behavior, future research would benefit from the availability of objective measures of behavior, for example driving parameters that indicate eco-driving (e.g., revolution speed, torque, acceleration). Such parameters could be collected by a device that records driving data (e.g., by CAN-Bus). However, our participants reported strong behavioral intentions and at the same time a considerably lower level of behavior maintenance; this suggests that they answered the self-reported behavior questions honestly (i.e., social desirability is not an important concern in the present study).

Second, the assessment of goals related to eco-driving focused exclusively on the goal of avoiding road-traffic noise. There might be other goals (e.g., fuel saving, minimizing $\mathrm{CO}_{2}$ emissions, accident prevention) that are related to eco-driving. Thus, future research should investigate whether goals other than avoiding the production of road-traffic noise are linked to the intention to practice eco-driving (e.g., safety, time and fuel saving as investigated by Dogan, Steg, \& Delhomme, 2011).

A third limitation is that our study design did not allow for causal conclusions. Although we used a longitudinal design with two measurement points, and although behavior and action control were assessed later than the other constructs, the variables intention to prevent road-traffic noise, behavioral intention, and implementation intention were assessed on the same measurement occasion. In future studies, these variables should be assessed across several occasions, ideally with at least one time point per variable examined. Another interesting option might be using an experimental design to investigate the causal flow within a model, as proposed by Bamberg (2013). Given that in the present research all constructs were simply measured, but not experimentally manipulated, future research might benefit from more rigorously testing the hypothesized causal effects between the constructs, for example when testing the mediation effect of implementation intention in the relation between behavioral intention and behavior.

Fourth, although we collected data from people of various ages and education levels, our sample was not a probability sample, and the survey was restricted to German-speaking residents of Switzerland. Thus, it is likely that our sample is not representative of car drivers in European countries, and future research should replicate the analyses using probability samples. Nevertheless, even if sample means differ from means in a representative sample, this does not necessarily affect the relations between variables (as captured by the path coefficients of the structural equation models).

Finally, although action control is an established construct in research on health behavior (Scholz, Nagy, et al., 2009; Sniehotta et al., 2005, 2006), its usability and validity for the investigation of driving behavior has to be examined in further studies. Moreover, given that both action control and behavior were measured at Time 2, it is possible that assessment-specific influences led to shared variance between the two constructs. This might have resulted in a somewhat stronger effect of action control on behavior. Nevertheless, it would not have been appropriate to assess action control at an earlier measurement occasion because action control cannot be assessed prospectively. Moreover, given that action control takes place simultaneously with the performed behavior, it is necessary to assess the two constructs with regard to the same time interval. For this reason, both behavior and action control were assessed retrospectively with a focus on the last four months.

\subsection{Conclusion}

Road-traffic noise is a severe environmental problem that affects the health and well-being of many individuals. One means of reducing road-traffic noise is to change motorists' driving behavior, specifically by establishing a low-noise driving style (i.e., eco-driving). In the present study, car drivers' motivation to prevent road-traffic noise and their motivation to practice eco-driving were rather high, but the two motivations were not connected. Therefore, communication focusing on the prevention of road-traffic noise should portray eco-driving as an efficient instrument for road-traffic noise prevention; and communication focusing on eco-driving should be complemented with the noise prevention aspect of eco-driving. Moreover, as the motivation to practice eco-driving does not necessarily lead to its practice, interventions should also prevent this good intention from draining away in everyday life. This could be accomplished by strengthening car drivers' active self-regulation (i.e. action control), for example by using prompts and behavioral feedback to enhance their constant awareness of their good intentions, as well as their implementation efforts.

\section{Acknowledgements}

This research was supported by the Swiss Federal Office for the Environment, Division of Noise and Non-Ionising Radiation, Bern, Switzerland, and Swiss National Science Foundation Grant PMCDP1_151423 to Elisabeth Lauper.

\section{References}

Abrahamse, W., Steg, L., Vlek, C., \& Rothengatter, T. (2005). A review of intervention studies aimed at household energy conservation. Journal of Environmental Psychology, 25, 273-291. 
af Wåhlberg, A. E. (2007). Long-term effects of training in economical driving: Fuel consumption, accidents, driver acceleration behavior and technical feedback. International Journal of Industrial Ergonomics, 37, 333-343.

Ajzen, I. (1991). The theory of planned behavior. Organizational Behavior and Human Decision Processes, 50, $179-211$.

Arbuckle, J. L. (2006). Amos (version 7.0) [computer program]. Chicago: SPSS.

Armitage, C. J., \& Conner, M. (2001). Efficacy of the theory of planned behaviour: A meta-analytic review. British Journal of Social Psychology, 40, 471-499.

Bamberg, S. (2007). Is a stage model a useful approach to explain car drivers' willingness to use public transportation? Journal of Applied Social Psychology, 37, 1757-1783.

Bamberg, S. (2013). Changing environmentally harmful behaviors: A stage model of self-regulated behavioral change. Journal of Environmental Psychology, $34,151-159$.

Bamberg, S., Hunecke, M., \& Blöbaum, A. (2007). Social context, personal norms and the use of public transportation: Two field studies. Journal of Environmental Psychology, 27, 190-203.

Bamberg, S., \& Möser, G. (2007). Twenty years after Hines, Hungerford, and Tomera: A new meta-analysis of psycho-social determinants of proenvironmental behaviour. Journal of Environmental Psychology, 27, 14-25.

Bamberg, S., \& Schmidt, P. (2003). Incentives, morality, or habit? Predicting students' car use for university routes with the models of Ajzen, Schwartz, and Triandis. Environment and Behavior, 35, 264-285.

Barkenbus, J. N. (2010). Eco-driving: An overlooked climate change initiative. Energy Policy, 38, $762-769$.

Barth, M., \& Boriboonsomsin, K. (2009). Energy and emissions impacts of a freeway-based dynamic eco-driving system. Transportation Research Part D: Transport and Environment, 14, 400-410.

Beusen, B., Broekx, S., Denys, T., Beckx, C., Degraeuwe, B., Gijsbers, M., et al (2009). Using on-board logging devices to study the longer-term impact of an eco-driving course. Transportation Research Part D: Transport and Environment, 14, 514-520.

Boriboonsomsin, K., Barth, M., \& Vu, A. (2011). Evaluation of driving behavior and attitude towards eco-driving: A southern California limited case study. Paper presented at the 90th annual meeting of transportation research board, Washington, D.C.

Castanier, C., Deroche, T., \& Woodman, T. (2013). Theory of planned behaviour and road violations: The moderating influence of perceived behavioural control. Transportation Research Part F: Traffic Psychology and Behaviour, 18, 148-158.

Chow, S., \& Mullan, B. (2010). Predicting food hygiene. An investigation of social factors and past behaviour in an extended model of the Health Action Process Approach. Appetite, 54, 126-133.

Cristea, M., Paran, F., \& Delhomme, P. (2012). The role of motivations for eco-driving and social norms on behavioural intentions regarding speed limits and time headway. World Academy of Science, Engineering and Technology, 6, 1307-6884.

Cristea, M., Paran, F., \& Delhomme, P. (2013). Extending the theory of planned behavior: The role of behavioral options and additional factors in predicting speed behavior. Transportation Research Part F: Traffic Psychology and Behaviour, 21, 122-132.

Delhomme, P., Cristea, M., \& Paran, F. (2013). Self-reported frequency and perceived difficulty of adopting eco-friendly driving behavior according to gender, age, and environmental concern. Transportation Research Part D: Transport and Environment, 20, 55-58.

Dholakia, U., \& Bagozzi, R. (2002). Mustering motivation to enact decisions: How decision process characteristics influence goal realization. Journal of Behavioral Decision Making, 15, 167-188.

Dogan, E., Bolderdijk, J. W., \& Steg, L. (2014). Making small numbers count: Environmental and financial feedback in promoting eco-driving behaviours. Journal of Consumer Policy, 1-10.

Dogan, E., Steg, L., \& Delhomme, P. (2011). The influence of multiple goals on driving behavior: The case of safety, time saving, and fuel saving. Accident Analysis and Prevention, 43, 1635-1643.

Ecodrive.org. (2013a). Benefits of ecodriving. <http://www.ecodrive.org/en/what_is_ecodriving-/benefits_of_ecodriving/> (Retrieved 24.06.13).

Ecodrive.org. (2013b). The golden ruls of eco-driving. <http://www.ecodrive.org/en/what_is_ecodriving-/the_golden_rules_of_ecodriving/> (Retrieved 13.08.14).

Eidgenoessische Materialpruefungs- und Forschungsanstalt (1997). Bericht zum F+E-Projekt “Neues EMPA-Modell für Strassenlaerm”: Teil Quellenbeschreibung. Dübendorf, Switzerland: Eidgenoessische Materialpruefungs- und Forschungsanstalt.

Elliott, M. A., Armitage, C. J., \& Baughan, C. J. (2003). Drivers' compliance with speed limits: An application of the theory of planned behavior. Journal of Applied Psychology, 88, 964.

Elliott, M. A., Armitage, C. J., \& Baughan, C. J. (2007). Using the theory of planned behaviour to predict observed driving behaviour. British Journal of Social Psychology, 46, 69-90.

Ericsson, E. (2001). Independent driving pattern factors and their influence on fuel-use and exhaust emission factors. Transportation Research Part D: Transport and Environment, 6, 325-345.

Ericsson, E., Larsson, H., \& Brundell-Freij, K. (2006). Optimizing route choice for lowest fuel consumption: Potential effects of a new driver support tool. Transportation Research Part C: Emerging Technologies, 14, 369-383.

Fischer, C. (2008). Feedback on household electricity consumption: A tool for saving energy? Energy Efficiency, 1, 79-104.

Fishbein, M., \& Ajzen, I. (2010). Predicting and changing behavior: The reasoned action approach. New York: Psychology Press.

Forward, S. E. (2009). The theory of planned behaviour: The role of descriptive norms and past behaviour in the prediction of drivers' intentions to violate. Transportation Research Part F: Traffic Psychology and Behaviour, 12, 198-207.

Fricke, N., \& Schießl, C. (2011). Encouraging environmentally friendly driving through driver assistance: The EcoMove project. In Proceedings of the sixth international driving symposium on human factors in driver assessment, training and vehicle design (pp. 394-400). Iowa City, IA: University of Iowa.

Gärling, T., Fujii, S., Gärling, A., \& Jakobsson, C. (2003). Moderating effects of social value orientation on determinants of proenvironmental behavior intention. Journal of Environmental Psychology, 23, 1-9.

Harland, P., Staats, H., \& Wilke, H. A. M. (1999). Explaining proenvironmental intention and behavior by personal norms and the theory of planned behavior. Journal of Applied Social Psychology, 29, 2505-2528.

Heath, Y., \& Gifford, R. (2002). Extending the theory of planned behavior: Predicting the use of public transportation. Journal of Applied Social Psychology, 32, $2154-2189$.

Hu, L. T., \& Bentler, P. M. (1998). Fit indices in covariance structure modeling: Sensitivity to underparameterized model misspecification. Psychological Methods, 3, 424-453.

Hu, L. T., \& Bentler, P. M. (1999). Cutoff criteria for fit indexes in covariance structure analysis: Conventional criteria versus new alternatives. Structural Equation Modeling, 6, 1-55.

Jenness, J. W., Singer, J., Walrath, J., \& Lubar, E. (2009). Fuel economy driver interfaces: Design range and driver opinions (Task 1 and Task 2 Report). National Highway Traffic Safety Administration, Washington, DC. DOT HS. <www.nhtsa.gov/DOT/NHTSA/NRD/Multimedia/PDFs/Crash\%20Avoidance/2009/ 811092.pdf> (Retrieved 03.09.14).

Kline, R. B. (2011). Principles and practice of structural equation modeling. New York, NY: Guilford.

Klöckner, C. A., \& Blöbaum, A. (2010). A comprehensive action determination model: Toward a broader understanding of ecological behaviour using the example of travel mode choice. Journal of Environmental Psychology, 30, 574-586.

Lehman, P. K., \& Geller, E. S. (2004). Behavior analysis and environmental protection: Accomplishments and potential for more. Behavior and Social Issues, 13 , $13-32$.

Mosler, H.-J., \& Tobias, R. (2007). Umweltpsychologische Interventionsformen neu gedacht. Umweltpsychologie, 11, 35.

Orbell, S., Lidierth, P., Henderson, C., Geraert, N., Uller, C., Uskul, A. K., et al (2009). Motivation and behaviour change following the ban on smoking in public places in England: A prospective community study. Health Psychology, 28, 753-761. 
Parker, D., Manstead, A. S. R., Stradling, S. G., Reason, J. T., \& Baxter, J. S. (1992). Intention to commit driving violations: An application of the theory of planned behavior. Journal of Applied Psychology, 77, 94.

Schafer, J. L., \& Graham, J. W. (2002). Missing data: Our view of the state of the art. Psychological Methods, 7, 147-177.

Schießl, C., Fricke, N., \& Staubach, M. (2013). Identification and analysis of motives for eco-friendly driving within the eco-move project. Intelligent Transport Systems, IET, 7, 46-54.

Schlachter, I., Meloni, T., Moser, S., Lauper, E., Fischer, M., \& Kaufmann-Hayoz, R. (2012). Reducing road traffic noise: How to design effective individualbased interventions. In InterNoise (Vol. 12, pp. 8761-8767).

Scholz, U., Keller, R., \& Perren, S. (2009). Predicting behavioral intentions and physical exercise: A test of the health action process model at the intrapersonal level. Health Psychology, 28, 702-708.

Scholz, U., Nagy, G., Göhner, W., Luszczynska, A., \& Kliegel, M. (2009). Changes in self-regulatory cognitions as predictors of changes in smoking and nutrition behaviour. Psychology and Health, 24, 545-561.

Scholz, U., Sniehotta, F. F., \& Schwarzer, R. (2005). Predicting physical exercise in cardiac rehabilitation: The role of phase-specific self-efficacy beliefs. Journal of Sport and Exercise Psychology, 27, 135-151.

Schultz, P. W., Oskamp, S., \& Mainieri, T. (1995). Who recycles and when? A review of personal and situational factors. Journal of Environmental Psychology, $15,105-121$.

Schüz, B., Sniehotta, F. F., \& Schwarzer, R. (2007). Stage-specific effects of an action control intervention on dental flossing. Health Education Research, 22, $332-341$.

Schwarzer, R. (2008). Modeling health behavior change: How to predict and modify the adoption and maintenance of health behaviors. Applied Psychology, $57,1-29$.

Schwarzer, R., Schüz, B., Ziegelmann, J. P., Lippke, S., Luszczynska, A., \& Scholz, U. (2007). Adoption and maintenance of four health behaviors: Theory-guided longitudinal studies on dental flossing, seat belt use, dietary behavior, and physical activity. Annals of Behavioral Medicine, 33, $156-166$.

Sniehotta, F. F., Nagy, G., Scholz, U., \& Schwarzer, R. (2006). The role of action control in implementing intentions during the first weeks of behaviour change. British Journal of Social Psychology, 45, 87-106.

Sniehotta, F. F., Scholz, U., \& Schwarzer, R. (2005). Bridging the intention-behaviour gap: Planning, self-efficacy, and action control in the adoption and maintenance of physical exercise. Psychology and Health, 20, 143-160.

Steg, L., van den Berg, A. E., \& De Groot, J. I. M. (2012). Environmental psychology: An introduction (Author Ed.). Oxford, UK: John Wiley \& Sons.

Swiss Federal Office for the Environment (2014). Lärmbelastung durch Strassenverkehr in der Schweiz: Zweite nationale Lärmberechnung, Stand 2012. [Noise exposure through road-traffic: Second national noise calculation, stand 2012]. Bern, Switzerland: Author.

van der Voort, M., Dougherty, M. S., \& van Maarseveen, M. (2001). A prototype fuel-efficiency support tool. Transportation Research Part C: Emerging Technologies, 9, 279-296.

Vlek, C. (2005). "Could we all be a little more quiet, please?" A behavioural-science commentary on research for a quieter Europe in 2020. Noise and Health, 7, 59-70.

Wall, R., Devine-Wright, P., \& Mill, G. A. (2007). Comparing and combining theories to explain proenvironmental intentions: The case of commuting-mode choice. Environment and Behavior, 39, 731-753.

Wallén Warner, H., \& Åberg, L. (2006). Drivers' decision to speed: A study inspired by the theory of planned behavior. Transportation Research Part F: Traffic Psychology and Behaviour, 9, 427-433.

Webb, T. L., \& Sheeran, P. (2006). Does changing behavioral intentions engender behavior change? A meta-analysis of the experimental evidence. Psychological Bulletin, 132, 249-268.

World Health Organization (1999). Guidelines for community noise. Geneva, Switzerland: Author.

World Health Organization (2009). Night noise guidelines for Europe. Copenhagen, Denmark: Author.

Wu, C., Zhao, G., \& Ou, B. (2011). A fuel economy optimization system with applications in vehicles with human drivers and autonomous vehicles. Transportation Research Part D: Transport and Environment, 16, 515-524. 